\title{
Hypermnesia for Socratic stimuli: The growth of recall for an internally generated memory list abstracted from a series of riddles
}

\author{
MATT ERDELYI \\ Brooklyn College, City University of New York, Brooklyn, New York 11210 \\ HERMAN BUSCHKE \\ The Saul R. Korey Department of Neurology and Rose F. Kennedy Center for Research in Mental \\ Retardation and Human Development and the Department of Neurosciences, Albert Einstein College of \\ Medicine, Bronx, New York 10461 \\ and \\ SHIRA FINKELSTEIN \\ Graduate Center, City University of New York, New York, New York 10036
}

\begin{abstract}
Hypermnesia (the increase of recall with time and effort) was tested and contrasted for three conditions of input, each thought to involve different levels of cognitive processing. The basic design involved a multitrial free recall procedure, with groups differing only in the presentation of materials to be remembered. The words subjects (most superficial cognitive processing) recalled a serial list of 40 words; the pictures subjects recalled the same series of 40 pictures; and the Socratic subjects (deepest cognitive processing) recalled an internally generated memory set consisting of covert solutions to 40 riddles, which had been pretested to yield the same 40 items as those of the other groups. While all groups showed spontaneous recovery of additional items on repeated recall without further presentation, as well as faster retrieval rates in early portions of successive recall trials, the increase in the number of items recalled on each trial was greatest for the Socratic group, intermediate for the pictures group, and least for the words group, suggesting that the greater the depth of cognitive processing, the greater the magnitude of hypermnesia.
\end{abstract}

In recent, hitherto independent research, Buschke and his associates (Buschke, 1973, 1974a, b, 1975a, b, 1976, in press; Fuld \& Buschke, in press; Ritter \& Buschke, 1974) and Erdelyi and his associates (Erdelyi \& Becker, 1974; Erdelyi, Finkelstein, Herrell, Miller, \& Thomas, in press; Shapiro \& Erdelyi, 1974; Erdelyi \& Kleinbard, Note 1) have demonstrated that recall may be hypermnesic. Despite numerous and quite significant differences in procedure, both experimental approaches have yielded sizable increments of recall on repeated testing without further presentation.

One recurring difference has been observed, however, in the two programs' otherwise converging pattern of results. While Erdelyi and his colleagues have typically obtained powerful hypermnesias with picture stimuli, they have usually found merely constant memory

This research was supported by PHS/NIMH Grant MH-25876 and by the City University of New York Research Award Program Grants RF-10704 and RF-11189 to the senior author, and USPHS Grants MH-17733 to the second author from NIMH, NS-03356 from NINDS, and HD-01799 from NICHHD. Requests for reprints should be addressed to Matt Erdelyi, Department of Psychology, Brooklyn College, CUNY, Brooklyn, New York 11210. functions with word lists. (A recently published independent replication by Madigan, 1976, corroborates findings of hypermnesia for pictures and not for words.) Buschke, on the other hand, has so far worked only with word stimuli, but has had no difficulty in obtaining "spontaneous remembering" of words across multiple recall tests. The surprising divergence in otherwise consonant findings prompted the present study.

The present authors' initial concern with the actual format of the stimulus list, pictorial vs verbal, gave rise, paradoxically, to a memory experiment with, strictly speaking, no external stimulus list whatever. The study arose from an interest in the possibility that word stimuli relative to picture stimuli might be accorded different depths of cognitive processing (Craik \& Lockhart, 1972), depending on the subjects' attitudes and motivations, and could therefore potentially explain variations in subsequent word recall. This supposition arose from an impression that the subject has greater cognitive control over his processing of verbal as compared to pictorial presentations, for it seemed, on the basis of the present authors' subjective experiences, as well as those of some subjects, that pictures are more "obligatory" stimuli than are words, being more prone to activate full-depth processing to 
the point of semantic abstraction. Consider the following, somewhat extreme example. Suppose a subject is staring intently at a stimulus, and that the stimulus in question is a simple picture. In this situation, it would be difficult to imagine the subject's failing to "see" the picture in both form and meaning. But now suppose instead that the stimulus is a verbal item such as a sentence or perhaps even a word. In that case, the subject might not necessarily "see" the item (in the "deeper sense"), since it requires an active, albeit a highly practiced cognitive decision to "read" the stimulus for it to be semantically apprehended.

While at first the present authors considered manipulating instructional and motivational factors to induce deep processing, it ultimately became clear that the only certain way to avoid passive, superficial processing of input was to eliminate the input altogether; instead, the subjects were to generate their memory items internally by actively constructing the memory list from a set of experimenter-provided hints, in the form of riddles, about the identity of each target item.

A "Socratic" list of items was therefore devised, which the subjects inferred by solving the riddles provided by the experimenter. It was insured that a uniform internal set would be generated, by pretesting the riddles, whose answers constituted the memory items. For example, the Socratic group (in contrast to a pictures and a words group) abstracted the target item "bat" from the riddle: "This longish wooden object is used by baseball players to hit the ball. What is it?"

\section{METHOD}

\section{Subjects}

A total of 45 subjects, randomly assigned to one of three groups of 15 subjects each, served in the experiment. Fifteen males and 30 females participated, distributed as follows in three groups: 7 males and 8 females in the pictures group, and 4 males and 11 females in both the words and riddles groups. The subjects were volunteers from introductory psychology courses at Brooklyn College and they obtained course credit for their participation. The subjects were tested in small subgroups of from three to five subjects each.

The experiment featured three independent input conditions (pictures, words, riddles), with five repeated tests of recall within each group. The three independent groups differed in the type of stimulus format to which they were exposed, even though the ultimate memory set of 40 items was identical in all three cases. The words subjects were presented a series of 40 concrete nouns, one at a time. The pictures subjects were identically treated except that the stimuli comprised the picture versions of the concrete nouns (e.g., a sketch of a bat instead of the word "bat"). The riddles, or Socratic group, were exposed to a series of typed riddles whose solutions (not the riddles themselves) corresponded to the memory items in the words and pictures groups. The Socratic subjects were told to remember the silent items for subsequent recall. The riddles had been pretested on previous pilot subjects to insure ease and unanimity of solutions. In all cases, the materials, whether
}

pictures, words, or riddles were presented on slides, by means of a Kodak carousel projector for $5 \mathrm{sec}$ each.

\section{Procedure}

The procedure was essentially identical for the three groups except for the type of materials shown. After a brief introduction to the experiment, in which subjects were asked to remember as many of the items as possible (i.e., pictures, words, or riddle solutions), the stimuli were presented to the subjects. After the input phase, which lasted about $3.5 \mathrm{~min}(5 \mathrm{sec}$ for each of 40 items), recall sheets containing 40 blank spaces were distributed to all subjects. The subjects were then instructed to write as many of the items as they could remember into the response blanks on their recall sheet, in any order. The pictures subjects were to write the names of the pictures. (The instructions at this juncture had the additional function of minimizing possible recency effects.)

The subjects were told that if they could not recall all 40 items they were nevertheless to fill in all 40 recall blanks, if necessary with nonrepeating guesses. This forced recall procedure was utilized to control for potential fluctuations in reporting criteria across recall trials (see Buschke, 1975b; Erdelyi, 1970; Erdelyi \& Becker, 1974; Ritter \& Buschke, 1974). The subjects were told that they would have $5 \mathrm{~min}$ to complete all 40 recalls (including any guesses). To help the subjects pace themselves, the passage of each minute was announced by the experimenter in all of the recall trials. If any subject had not produced 40 responses by the end of the $5-\mathrm{min}$ period (which sometimes happened in the first recall trial, but not on the subsequent ones), an extra minute of "grace" was allowed. The handful of subjects (about one or two per group) who failed to complete all $\mathbf{4 0}$ responses within this time limit were discarded; thus, all 45 subjects included in the study completed their 40 responses within at most $6 \mathrm{~min}$. After the completion of the first recall trial $\left(R_{1}\right)$ the completed recall sheets were collected and new blank ones handed out. The subjects were briefly instructed to attempt another free recall $\left(R_{2}\right)$ of the original items, and again to complete the 40 responses within $5 \mathrm{~min}$, at which time the recall sheets were collected. This procedure was repeated for the remaining recall trials $\left(R_{3}\right.$, $\mathbf{R}_{4}$, and $\mathbf{R}_{5}$ ).

\section{RESULTS}

Figure 1 presents the recall curves for the three groups, that is, the average number of correct recalls (whether generated as veridical recalls or guesses) for each of the five successive trials. It will readily be seen that the general trend of recall was incremental for all groups, though the Socratic group exhibited the steepest increase of recall over time and recall trials. An analysis of variance (stimulus condition by recall trials) yielded a highly significant main effect for recall trials $[F(4,168)=15.69, p<.01]$, although the interaction of Stimulus Condition by Recall Trials fell short of significance $[F(8,168)=1.57]$. Overall differences in recall as a function of stimulus condition were also nonsignificant $[\mathrm{F}(2,42)<1]$.

To evaluate recall by each group, tests for simple effects were carried out on recall performance over trials for each type of presentation. The analyses revealed that, while the Socratic group $[F(4,168)=12.78$, $p<.01]$ and the pictures group $[F(4,168)=4.34$, $p<.01]$ produced significant recall increments, the 


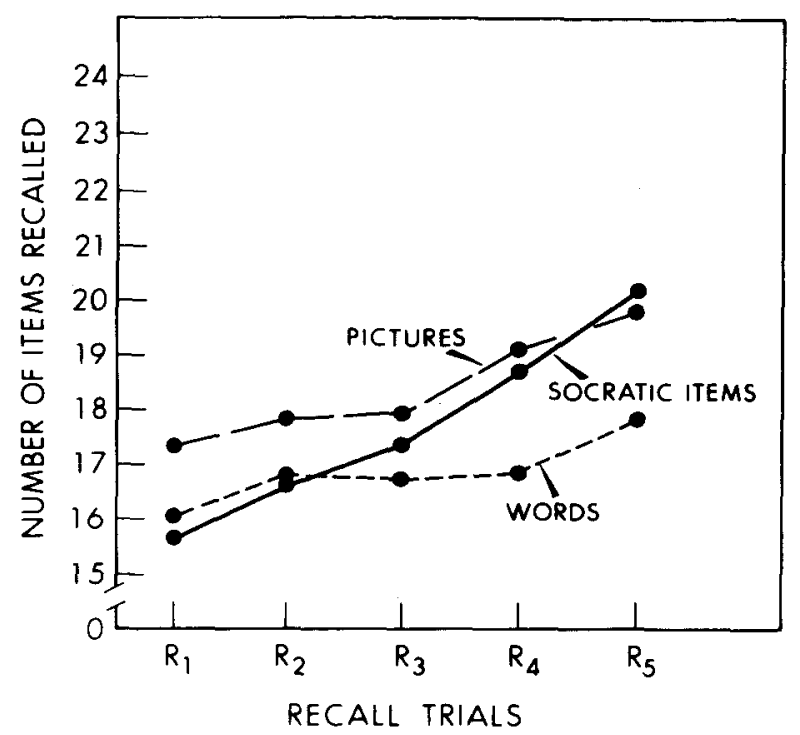

Figure 1. Number of words, pictures, and Socratic items recalled on each trial.

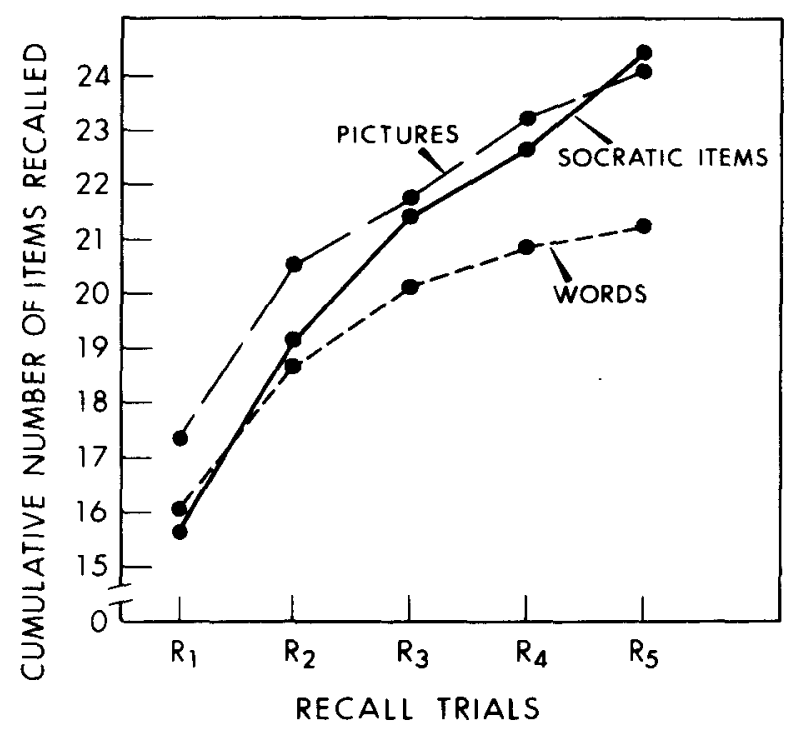

Figure 2. Cumulative number of different words, pictures, and Socratic items recalled at least once.

words group did not, despite a numerical increase $[\mathrm{F}(4,168)=2.02, \mathrm{p}=.10]$

A test for differences in linear trends revealed that the recall of Socratic items increased more than did recall of words $[F(1,168)=11.26, p<.01]$ or of pictures $[F(1,168)=4.66, p<.05]$, while recall of pictures was not significantly more incremental than was recall of words $[F(1,168)=1.43$, n.s. $]$. The results suggest that recall for Socratic items was not only hypermnesic, but was more hypermnesic than that of either the pictures or words groups. Although recall of the pictures increased over trials, as in previous studies, recall of words in this instance did not increase significantly. However, the absence of a significant increase in the number of words recalled on repeated trials need not imply that additional words were not recovered spontaneously over recall trials, since it is possible that spontaneous recoveries were masked by a roughly equivalent number of losses. It is, therefore, necessary to examine the total number of different items recalled cumulatively across recall trials. Figure 2 , which shows the total number of different items recalled at least once, reveals clearly that all groups, including the words group, recovered additional items over repeated recall trials without further presentation, and that the initial recall trial did not exhaust the information retained in long-term memory (see also Ballard, 1913; Breuer \& Freud, 1895/1966; Brown, 1923; Buschke, 1973, 1974a, b, 1975a, b, in press: Erdelyi \& Becker, 1974; Fuld \& Buschke, in press; Tulving \& Pearlstone, 1966).

Finally, it may be of interest to address a question hitherto unposed by previous research: How does retrieval rate within a recall trial vary as a function of repeated testing? Figure 3 presents the average number of items correctly recalled as a function of minutes elapsed in each of the five successive trials. It is clear from the recall rate profiles for each trial that, with successive recall attempts, more and more of the recalled items are generated in the first few minutes, and fewer and fewer in the later minutes. It would appear, therefore, that, with repeated testing, retrieval rate for most items becomes progressively faster, with more and more of the retrievals occurring in the earlier portions of the recall trial.

\section{DISCUSSION}

In the Socratic method of instruction, the role of the teacher is not to impart answers but rather to raise questions. While the procedure may be super-

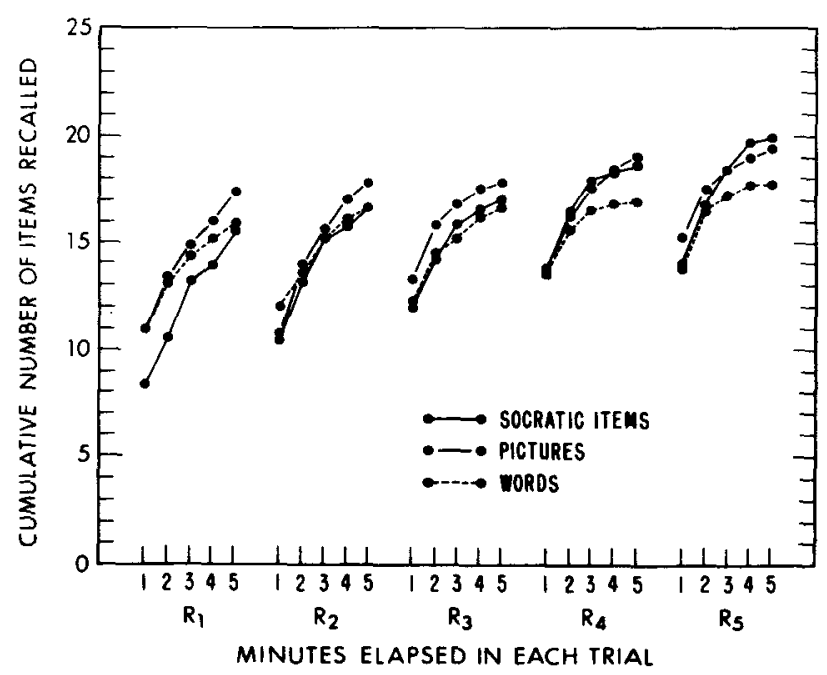

Figure 3. Rate of retrieval of words, pictures, and Socratic items in each trial. 
ficially inefficient and even cumbersome in the short run, its rationale is that the learner benefits because he ultimately learns more, and more profoundly, when he is prompted to discover the answers for himself, than when he is spoon-fed the answers. It was specifically this quality of profound acquisition that prompted the present authors to adopt the Socratic technique for assessing the effects of deep (profound) processing in hypermnesia.

The results seem to be consistent with what one might expect from the Socratic technique. Despite the poorer initial performance, the Socratic subjects reached and (at least numerically) surpassed the recall performance of subjects in the other groups by the last recall trial. Recall increased significantly more for Socratic items than for either pictures or words. At the same time, no significant group differences were obtained in overall recall performance. An obvious question for future research is whether Socratic subjects would ultimately perform better than pictures and words subjects if given more extensive time periods and recall trials than in the present single-hour laboratory period. In recent work, Erdelyi and Kleinbard (Note 1) have shown that picture recall increases substantially (on the average by more than $50 \%$ ) over a period of a week. The fact that Socratic items were more hypermnesic than were pictures in the present study suggests that even greater long-term hypermnesias might be achieved with this type of deep stimulus material.

While the outcome of the present study obviously raises numerous questions, as, perhaps, a study employing the Socratic technique should, the data do seem to provide a definitive answer to the initial question: Hypermnesia is not a phenomenon restricted to pictorial stimuli. Other presentations, such as Socratic stimuli, may result in even more hypermnesia.

At the same time, the present data do not fully resolve the discrepant past results obtained with word stimuli by Erdelyi and Buschke. Erdelyi, usually using fewer than five recall trials (three, as a rule), has generally obtained no hypermnesia with words (except when subjects are explicitly instructed to image the verbal input; see Erdelyi, Finkelstein, Herrell, Miller, \& Thomas, in press), while Buschke, usually using more than five recall trials, has consistently obtained hypermnesia. With the present five recall trials, there was a marginal $(p=.10)$ hypermnesia effect with words, which may or may not have become significant with additional trials. All in all, it is becoming increasingly clear that the answer is not simple; numerous factors other than the actual stimulus format, including type and depth of stimulus coding, and the time and extent of recall effort, determine whether hypermnesia is or is not obtained and to what extent.

\section{REFERENCE NOTE}

1. Erdelyi. M. H., \& Kleinbard, J. Has Ebbinghaus decayed with time? The growth of recall (hypermnesia) over days. Manuscript submitted for publication, 1976.

\section{REFERENCES}

Ballard, P. B. Oblivescence and reminiscence. British Journal of Psychology Monograph Supplements, 1913, 1, VI-82.

Breuer, J.. \& Freud, S. [Studies on hysteria] (J. Strachey, Ed. and trans.). New York: Avon, 1966. (Originally published, 1895)

Brown, W. To what extent is memory measured by a single recal1? Joumal of Experimental Psychology, 1923, 6. 377-385.

Buschke, H. Selective reminding for analysis of memory and learning. Journal of Verbal Learning and Verbal Behavior, 1973, 12. 543-550.

Buschke. H. Spontaneous remembering after recall failure. Science, 1974, 184, 579-581. (a)

BusCHKE, H. Retrieval in verbal learning. Transactions of the New York Academy of Sciences, 1974, 36, 721-729. (b)

Buschke, H. Short-term retention, learning, and retrieval from long-term memory. In D. Deutsch \& J. A. Deutsch (Eds.), Short-term memory. New York: Academic Press, 1975. Pp. 73-106. (a)

Buschke. H. Retrieval of categorized items increases without guessing. Bulletin of the Psychonomic Society, 1975, 5, 71.73. (b)

BuschKe, H. Retrieval in the development of learning. In N. J. Castellan, D. B. Pisoni, \& G. R. Potts (Eds.), Cognitive theory: (Vol. II). Hillsdale, N.J: Lawrence Eribaum, in press.

BUSCHKE, H. Learning is organized by chunking. Journal of Verbal Learning and Verbal Behavior, 1976, 15, 313-324.

CRAIK, F. I. M., \& LoCKHART, R. S. Levels of processing: A framework for memory search. Joumal of Verbal Learning and Verbal Behavior, 1972, 11, 671-684.

ERDELYI, M. H. Recovery of unavailable perceptual input. Cognitive Psychology, 1970, 1, 99-113.

ERDELYI, M. H., \& BeCKeR, J. Hypermnesia for pictures: Incremental memory for pictures but not words in multiple recall trials. Cognitive Psychology, 1974, 6, 159-171.

Erdelyi, M. H., Finkelstein, S., Herrell, N., Mirler, B., \& Thomas, J, Coding modality vs. input modality in hypermnesia: Is a rose a rose a rose? Cognition, 1976, in press.

Fuld, P. A., \& Buschke, H. Stages of retrieval in verbal learning. Journal of Verbal Learning and Verbal Behavior, in press.

MadigAN, S. Reminiscence and item recovery in free recall. Memory \& Cognition, 1976, 4, 233-236.

Ritter, W., \& Buschke, H. Free, forced, and restricted recall in verbal learning. Journal of Experimental Psychology, 1974, 103, 1204-1207.

Shapiro, S., \& ERDElyi, M. H. Hypermnesia for pictures but not words. Journal of Experimental Psychology, 1974, 103, $1218-1219$.

Tulving, E., \& Pearlstone, $Z$. Availability versus accessibility of information in memory for words. Journal of Verbal Learning and Verbal Behavior, 1966, 5, 381-391.

(Received for publication October 13, 1976; revision accepted November $26,1976$. .) 